\title{
Fatigue strength of mortise and tenon furniture joints made from oil palm lumber and some Malaysian timbers.
}

\begin{abstract}
A study was undertaken to evaluate comparative bending and fatigue strengths of rectangular mortise and tenon furniture joints made from oil palm (Eleais guineensis) lumber against a few established furniture wood materials. This is owing to the fact that, although the rectangular mortise and tenon joints are the most commonly joints used in chair construction, studies on its strength under cyclic loading is very limited. The fact that furniture joints are the weakest link in the furniture structure, it is necessary to establish its strength performance especially under repeated loading as experienced by the chair in service. The results showed that the bending strength of the oil palm lumber joints were half the strength of the wooden joints. However, in terms of fatigue strength, joints made from oil palm lumber showed comparable performance with the other wood materials. The results also showed that the allowable design stresses for rectangular mortise and tenon joints could be set at $20 \%$ of its bending strength. This study has far reaching implications on furniture engineering as it suggest that proper joint design is mandatory not only to ensure the furniture's reliability in service, but also improve its aesthetic and production imperatives.
\end{abstract}

Keyword: Static strength; Fatigue; Mortise and tenon; Furniture; Oil palm lumber; Wood. 